\title{
JOB SATISFACTION AS AN INDICATOR OF THE QUALITY OF EMPLOYMENT*
}

(Received 11 June, 1974)

\begin{abstract}
It is suggested that the quality of employment should be assessed from the value perspectives of the employer and of society as well as the perspective of the worker. The prevailing conception of the nature of job satisfaction, and the associated measurement methods, provide useful but unnecessarily limited indicators of the quality of employment. An enlarged conception is offered as to the nature of job satisfaction, its causes, and its possible consequences. The implications of this conception for the utility of satisfaction measures as social indicators are examined as to three aspects: (1) The psychology of job satisfaction; (2) The sociology of job satisfaction; (2) The approach and technology of using subjective satisfaction measures in conjunction with other indicators. The view is expressed that direct measures of subjective job satisfaction are an essential component in any effort to make comparisons or monitor changes in the quality of employment, but that such measures, like other subjective and objective indicators, have ambiguous meaning if used alone.
\end{abstract}

The remarks offered in this paper must be understood within the context of the political, social and scientific interests from which they arise. Social commentary in many countries of late has included the notion that that the continuous monitoring of the quality of life in a society must be enlarged from the familiar base of economic system surveillance to include other important aspects of the social system and of the individual lives of its members. We have become accustomed to the use of various economic indicators such as the gross national product, the relative growth rates of family income and consumer prices, the trends in amount of money available for discretionary spending, and the like. These are valued indicators. We have become quite adept at the technology of their use and confident - perhaps too confident - of their meanings. We have become accepting of the fact that the same set of indicators may lead to some variety of conflicting prescriptions and predictions; that is, the data do not compel any particular course of action for a citizen or for his society, but they do permit informed debate and the better choice of issues for debate. It is argued that we need comparable indicators and competence in their use with respect to other aspects of society. What these 
other aspects shall be is still under discussion, but among those frequently mentioned are: community, family, leisure, health. The quality of employment (or, more broadly, the quality of working life) is included in all such lists on the simple grounds that work is prevalent, it occupies a large part of the available time of adults, and it has ramifications affecting virtually all other aspects of the quality of life.

The monitoring of the quality of employment is likely to be advanced rather more quickly than effective monitoring in some other areas. The technology appears to be within our reach, although not yet within our firm grasp. The politically and economically interested parties are alerted and are organized in a way that makes action possible. Work to this end is in progress with public subsidy in several countries, including yours and mine. Institutions are emerging to house the effort, and coordinating machinery, both domestic and international, is beginning to appear. ${ }^{1}$ Academic social science institutions have become engaged, and it is significant that the justification is as much on grounds of public need as on grounds of scientific priority. The values invoked, while mainly those of political and social ends, include the recognition that societal wellbeing, political processes, and scientific advancement are, for better or for worse, inevitably entangled with one another.

The purposes of this paper are less grand in scope than the preamble suggests. I shall attempt four tasks:

(1) to clarify three of the conceptual issues that seem basic to effective assessment of the quality of employment; (2) to comment critically upon the currently-popular conception of the nature of job satisfaction and its role as a social indicator; (3) to suggest a broader view of the nature of job satisfaction - one that bears upon its measurement, its central meaning in the assessment of quality of employment, and upon its function in the maintenance of society; (4) to suggest some priorities for research and action during the next years.

The three conceptual issues to be raised are among those that must be taken into account in any long-term program for monitoring the quality of employment and in programs for actively seeking improvement in the quality of employment. Two of the issues have a somewhat technical character as they concern matters of how we shall best measure the quality of employment, and whether the measures shall focus upon the individual and his job or upon the conditions and changes that prevail in the society 
as a whole. These will be deferred until later. First attention will be given to an issue of value and purpose: who shall judge the quality of employment and what values should be invoked ? ${ }^{2}$

\section{WHO SHALL JUDGE THE QUALITY OF EMPLOYMENT?}

The prevailing conception of the quality of employment is based upon the assumption that the individual's own experience of satisfaction or dissatisfaction defines the quality of his working life. That is, a 'good' job for a given individual is one which fits his needs, his preferences and his expectations, and the degree of fit is best judged by the occupant of the job. This proposition is usually elaborated with two associated ideas: (1) that the objective characteristics of the work situation induce corresponding attitudes of satisfaction or dissatisfaction, and (2) that the association between working conditions and satisfaction is not constant but is moderated by attributes of the individual that bear upon his abilities, values and expectations.

While few would want to defend this pair of propositions as an adequate basis for understanding and improving the quality of employment, the power of the propositions should be acknowledged. They have provided the framework for most of our inquiry into the quality of working life. Most of what we know derives from a persistent testing of ideas that flow from these propositions. For the short-range future, these propositions and the quantitative data resulting from them will be our major source of guidance in efforts to improve the quality of working life. $^{3}$

The evidence bearing upon the validity and potency of these propositions is impressive and incontrovertible. It is estimated that perhaps as much as half of the variation in the job satisfaction of individuals is 'explained' by a relatively short roster of objective environmental conditions with respect to which their jobs vary. ${ }^{4}$ It is known that the degree of satisfaction with a given aspect of working conditions varies among individuals in ways that are systematic, measurable and in some degree predictable from differences in individual attributes. ${ }^{5}$ It is known that differences in significant public forms of behavior (e.g. quitting a job, changing a job, becoming ill, etc.) are linked with job satisfaction.

Nevertheless, we need to examine the limitations of such a conceptions 
of the quality of employment, and the directions of elaboration and supplement that are needed.

\section{I.1. Limitations of the Paradigm}

(1) The chief limitation of this prevailing conception is its exclusive reliance upon the expression of satisfaction by the individual worker as evidence of high quality of employment. This is a very narrow perspective with respect to the source and nature of the values to be employed.

(2) It assumes a very limited time perspective, and does not invite consideration of past conditions, future consequences.

(3) It assumes a very narrow scope of relevant factors, with relevancy defined by reference to the 'job' (as compared with 'working life' or 'career') and to the present attributes of the person as compared with his changing and potential attributes as he progresses through his life span.

(4) It assumes that a 'job' is an adequate entity for description and analysis of the environment of a person's working life, despite the obvious fact that jobs occur in sets, in sequences, and in otherwise organized interdependency with other jobs, and in interdependency with other nonjob roles.

(5) It is a static conception, with few allowances for inquiry or purposeful action with respect to changes in jobs and persons.

The common feature of these statements of limitation is their invitation to enlarge the consideration of quality of employment beyond the limits set by the individual worker's reaction to immediate experiences of an environment narrowly bounded in time, in physical space and in social space. While high importance, if not primacy, must be given to the individuals's personal values in assessing the quality of his own experience of his working life, it can be taken for granted that they are not sufficient. The individual is in many ways incapable of an adequate assessment of his own experiences, and there are other value perspectives to be invoked.

The individual worker, whatever his background and status, is in important respects incapable of optimum judgement of his own life situation. While his report of job satisfaction or dissatisfaction surely reflects a fundamental biological wisdom concerning the life-sustaining and lifeenhancing properties of his work environment, his report also contains elements of expediency, self-deception, ignorance, social pressure, and false beliefs about the world in which he lives. Hence, in our studies of the 
quality of working life, individuals can and do report satisfaction with work situations that we know (from information not accessible to the respondents) are abbreviating their lives, threatening their family relationships, and unnecessarily narrowing their future life options. Others can and do report dissatisfaction in work situations that display in high degree virtually all of the attributes that are generally valued by others and none that are plausibly accessible for 'improvement'. These are not trivial individual aberrations of judgement, but extreme cases that remind us of the frailty of all evaluations based exclusively upon one person's own values, own perceptions and own information resources. The basic values of individuals do not get expressed fully, nor in optimum combination, in their transient affective responses to a constricted range of stimuli presented by 'a job'. The aggregation of such responses, e.g. to get a social indicator, does not remove all of the 'error', for the error is in part built into the existing social structure of person-job relationships. Further, the quality of employment is not to be considered a wholly private affair of the job occupant, for there are at least two other perspectives that must be employed, each with distinctive and legitimate values. These additional value perspectives must be taken into account in social indicators and also when developing guidelines for ameliorative actions and programs.

\section{I.2. Social and Personal Priorities}

If priorities are to be assigned among various policies and programs intended to improve working conditions, the development and execution of these policies and programs will obviously be very costly. To justify the cost it must be anticipated that there is some resulting benefit. But who should be the beneficiary? Priorities should clearly be assigned to improving quality of employment with respect to those job facets that heighten the effectiveness of each worker. But from whose perspective should such effectiveness be judged? There are at least three distinct perspectives for evaluating effectiveness.

The first perspective, that of employers, assigns priorities in terms more relevant to the needs of those doing the employing rather than the needs of those who are employed. As a result many investigations of the determinants of employee effectiveness, not to mention employers' normal business and accounting records, emphasize productivity, quality of output, cost per unit of work done, and similar indicators of effectiveness. 
While these do reflect the self-interest values of employers, they also represent deeply-rooted values of the whole of the society.

A second perspective for assessing effectiveness is that of the worker himself. Workers form conclusions or expectations about their effectiveness in their work life not only in terms of actual work performance, but also in more general terms of the costs and benefits associated with their work role. Thus, a worker normally assesses his work role effectiveness in such familiar terms as earnings, access to promotions, avoidance of accident or discomfort, security, intrinsic satisfactions from the work done, and the like. $\mathrm{He}$, too, engages in something like a cost-benefit calculation, with consequences that include such behavior changes as quitting, working harder, seeking improvement in rewards, seeking qualifications for a 'better' job, and the like.

A third perspective can also be invoked: That of the community or the society. Some of the costs and benefits associated with an individual's work role effectiveness do not enter into the formal or informal accounting of either the employer or the worker. For example: Underutilized skills are lost to the economy; the laid-off worker drains the public budget; a local 'cost' of advanced skill training accrues to the manpower capital assets of the nation; the economic impact of a work stoppage falls in the end upon the public; the income-deficient worker burdens the society with a family prone to illness, future welfare costs, and substandard economic contribution.

Which of these three perspectives is the most appropriate one, for assessing the quality of employment or for resolving issues of costs and benefits in the allocation of priorities to policies and programs, is not a question that can be resolved by research. It is fundamentally one of values. No amount of research can determine whether it is 'better', for example, to have a docilely contented workforce that is under-producing to the degree that both workers and others in society resultingly suffer rather than to have a disgruntled, restless, unhealthy and even angry workforce whose behaviors nevertheless continue to raise the GNP, corporate profits, and the quality of their own lives as consumers. A decision as to which of these two situations (or, for that matter, any situation that represents an imbalance of perspectives) is the 'better' or 'best' one is most appropriately placed in the laps of those whose positions confer on them the legitimacy to make such value decisions. Research can 
at best help social planners such as managers, legislators and labor leaders to recognize which perspectives may at present be incompatible.

For purposes of priority-setting, the importance of any aspect of a work role, therefore, ultimately depends upon the magnitude of its impact upon a variety of effectiveness criteria, the differential significance of which is largely a matter of a somewhat arbitrary, but hopefully informed and humane, selection from among a possibility incompatible set of values. The measurement of the quality of employment, and the conduct of efforts to improve the quality of employment, therefore, rest most fundamentally upon the question of whose values shall be employed, who shall judge. Indicators of the quality of employment must include both those attributes of the work situation that are immediately valued and also those that are believed to have consequences that are valued. Employers might suggest that priority be given to those working conditions that directly affect the productivity of their workers. This view, however, is a very narrow one unless it is known that once productivity rises then all other desired outcomes will follow. Thus, a sound approach to the assessment of the quality of employment and to the improvement of employment, rests upon, first, an awareness of different and often incompatible values which must be balanced or compromised, and second, upon knowledge of the outcomes associated with different conditions of employment.

\subsection{The Structure of Effectiveness}

Table I presents an illustrative list of examples of 'outcomes' (e.g. selfesteem, turnover, productivity, life satisfaction, etc.) that are thought to be associated with objective conditions of employment (e.g. pay, hours of work, adequacy of equipment, etc.). They are listed according to their presumed principal interest to workers, to employers and to society-atlarge.

The assignment of an indicator to a particular perspective in Table $I$ is at times somewhat arbitrary and perhaps even uncharitable. The assignment does not mean to imply, for example, that from the point of view of employers the physical or mental disorders of their workers are of no importance, but only that from the perspective of most employers there are other more important outcomes. Conversely, the assignment does not imply that employees are necessarily indifferent to productivity. Indeed, the harder it is rationally to assign an outcome to a particular perspective 
TABLE I

Quality of employment outcomes from three perspectives

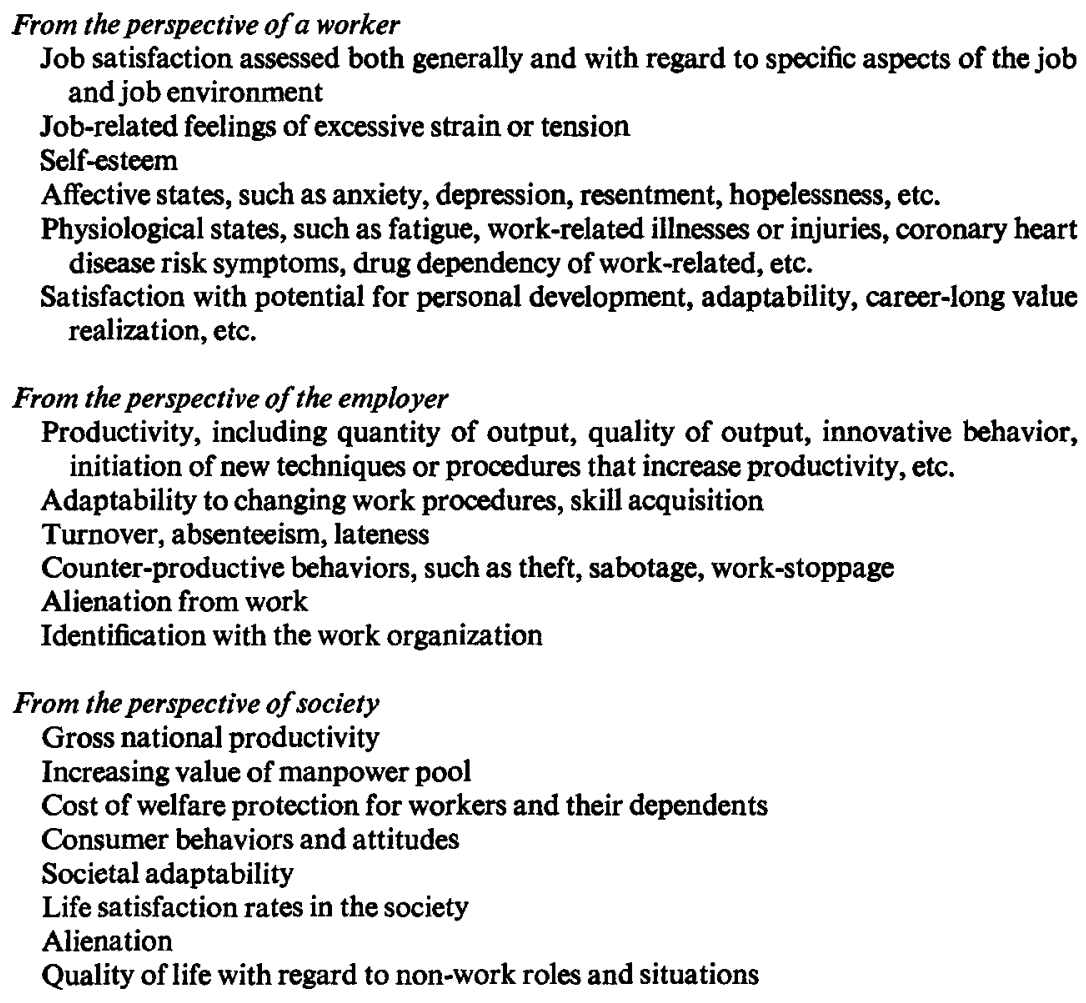

the more important that outcome is likely to be. According to this rule of thumb, priorities might profitably be assigned to measuring and improving those working conditions that affect outcomes that are patently relevant to all three perspectives. Work-related illnesses and injuries constitute a case in point. They are obviously important to the ill or injured worker, represent a cost to his employer (in terms, for example, of sick-pay and filling the worker's position while he is laid up), and are costly to society as well (e.g., in terms of a drain on a nation's scarce medical resources).

Few would debate the assertion that a high priority should be assigned to a particular improvement in working conditions that simultaneously effects a desired change with regard to all the outcomes listed in Table I. 
There is probably no such 'miracle cure' and, for lack of it, attention will have to be directed toward measurement and action programs with more circumscribed effects, each of which achieves desired results with regard to some outcomes, none with regard to some others, and even undesired consequences with regard to still others In this latter case matters of priorities and value perspectives become critical. Everyone, regardless of his own perspective may, for instance, be in agreement that outcome $A$ should be maximized. But disagreements stemming from different perspectives could emerge when it is discovered that undesired consequences would simultaneously be effected with regard to outcome $B$.

For this reason it is essential to know about the relationships among possible outcomes and about the causes of outcomes that lie in the nature of the work situation. Only when it is known what are the possible sideeffects of improving some aspect of working conditions to effect a positive change with regard to an outcome can all perspectives realistically be invoked. The unforeseeable side effects of any change need to be foreseeable. Therefore, a major requirement of future research is to provide better data than is presently available concerning the interrelations among outcomes such as those in Table I. What classes of outcomes 'go together' in the sense of being positively associated? Which are presently incompatible in the sense of being negatively associated? Which are completely independent? Which are nested hierarchically such that some are more general in character and include others? Which represent mainly different ways of measuring the same thing? Which, regardless of the form or degree of their associations, are independent in the sense that they are influenced by different aspects of quality of employment?

We should be warned that even where a number of outcomes might at first seem to be highly compatible and positively interrelated, data may indicate otherwise. For instance, Seashore, Indik, and Georgopoulos ${ }^{6}$ raise the issue of whether there is any empirical justification for assuming a unidimensional construct representing 'overall job performance' or 'net performance', and whether various separate measures of performance can be legitimately regarded as independent estimates of such a single inclusive variable. This assumption and the measurement strategy it implies leads to attempts to combine the elemental criteria through techniques which maximize a common factor, maximize the predictability of the joint elements, or weight the elements in accordance with their reliability 
or predictability. Logical and practical problems arise, however, from the common finding that some elements of job performance (or, more generally, of effectiveness in work roles) may be negatively correlated, that elements interact, and that any single estimate of overall performance does not reflect at all well the values implied by the original choice of elemental measures. The data provided by Seashore, Indik and Georgopoulos indicated such a condition; similar results concerning organizational, as compared with individual, performance outcomes are provided by Bowers and Seashore and by Yuchtman and Seashore. ${ }^{7}$ We can be confident of finding similar complexities in the domain of societal outcomes and values, not to mention in a larger domain defined by the values of individuals and employers as well as of society-at-large.

Nevertheless, there is surely some determinable structure of relationships among an array of valued outcomes such as is displayed in Table I, and it is essential that the nature of this structure be empirically determined or at least plausibly estimated.

\section{I.4. The Time Span of Measurement}

A further consideration in the definition and measurement of the quality of employment must be introduced at this point, namely, the time span of measurement. With very few exceptions, past efforts to assess the quality of working life, regardless of the value framework for assessment, have referred to a relatively brief time period. It is self evident, however, that individuals, employing organizations and societies in fact operate within a long time span; the quality of working life must accordingly be defined and measured with consideration for past events and conditions, changes and trends, delayed and distant consequences, predictions and expectations about the more distant future.

This point need not be elaborated here except to provide examples. Cobb and Rose ${ }^{8}$ have reported evidence that the physiological consequences of job stress in a certain stressful occupation are accumulative over a period of many years, with age-corrected hypertension rates, for example, increasing throughout the period studied; it is plain that any short-term association between working conditions and health in this and similar occupations would grossly underestimate the health outcomes. The reported high satisfaction of individuals in certain work roles (medical intern, for example) that embody working conditions that are 
normally unacceptable (low pay, low status, long hours) can be accounted for readily and realistically by viewing the work role in a lifetime span with short-term, negatively-valued conditions outweighed by confidently expected, positively-valued, future conditions. Yuchtman and Seashore ${ }^{9}$ report evidence that certain descriptors of organizational work environment are more closely associated with later than with concurrent outcomes.

The definition and measurement of the quality of working life thus requires consideration not only for diverse value perspectives, as descibed earlier, but also for value realizations that have differential time lags. These time lags must be determined, and another research priority is thus identified.

\section{I.5. Value Conflicts and Time Span of Measurement}

The conclusion from the foregoing remarks about value perspectives, about the connections between objective conditions of work situations, and about delayed consequences, is that any sound approach to the monitoring of the quality of employment will have, among other things, the following characteristics: (1) the central values of at least three value perspectives must be incorporated in the measurements; (2) We must know from inquiry, or at least make confident judgements, about the location and degree of value conflict that is to be clarified (not suppressed) by the indicators; (3) we must provide in the measurements and in their form of reporting for delayed consequences as well as immediate consequences arising from conditions of employment.

\section{WHAT DOES AN INDICATOR DESCRIBE?}

There is a strong temptation among social scientists and the general public to imagine that the quality of employment in a society will be sufficiently represented by the use of a few descriptive variables of an aggregative sort, if only we can with wisdom choose the right variables for the purpose. One thinks easily of a roster of indicators that might include, for example: rate of unemployment, amount and population distribution of earned income, rates of occupational illness and injury, average level of job satisfaction, frequency of promotions, duration of vacations, hours of work per week, and the like. This image of the nature 
and use of social indicators is an attractive one because of its simplicity and because each of the indicator variables seems, in its own right, to measure something of obvious meaning in the context of quality of employment. Who can question that more pay is better than less, that long vacations are better than short, that illness and accidents are deplorable? Still, this image needs to be questioned with respect to its fundamental assumptions, which are three in number. ${ }^{10}$

\section{II.1. The 'Obvious' Meaning of Indicators}

The seemingly obvious significance of many proposed social indicators arises largely because we find their meaning in our own personal life context and fail to take account of general societal and personal conditions that may affect the meaning. An index of national average earned income from employment can be taken to illustrate the point. One does not question that a rising index suggests a rising quality of employment for the nation, as it surely would for most of us individually. However, with respect to a nation such a conclusion would be in doubt if consumer prices were rising even faster, if more of the rewards for work were being included in pay but with more than offsetting reduction in indirect benefits, if the rise in average pay merely reflected the removal of large numbers of low-pay individuals into the category of 'unemployed and unpaid', if an increasingly large segment of the population is supported by fixed income from sources other than pay-for-work, if the national resources allocated to pay are sufficient to diminish the resources available for necessary maintenance of capital investments, or if ....

Similar remarks could be made about hours of work per week. Note that self-employed people who control their own hours choose on the whole to work more hours, not fewer; note that societal interests and employers' interests may favor more, not fewer, average hours per week. Hours of work per week may rise and fall across the nation for reasons, and with consequences for individuals, that make doubtful the meaning of the index when considered alone.

We will later discuss measures of job satisfaction showing that even such a measure of quality of employment, one that embodies many of the associated considerations, when aggregated to the national level contains ambiguities of meaning when considered alone. The valid meaning of job satisfaction at the societal level of aggregation rests upon having infor- 
mation about its causes and consequences, given the state of the society at that time in other respects. The valid meaning of average rate of pay at the societal level is to be found only in the context of some theories or models about the optimum allocation of goods and services among the population as a whole over some reasonable span of time.

\section{II.2. The Unit of Analysis for Policy Implications}

Social scientists are in the habit, more than the general public, of living in a mental world comprised of discrete variables rather than in a world of systems of interdependent variables. This is not simply from lack of insight, but because our work normally requires that we search out the dimensionality of events and conditions. The price we pay is that we risk doing some violence to the intactness and integrity of natural systems.

In the context of monitoring the quality of employment, this raises the following dilemma: shall we monitor the quality of employment as it is directly experienced by the individual worker, or at the level of the work place (firm, or industry), or at the level of the society as a whole? We earlier made the point that different values come into play according to the 'level' of description that is intended. Additionally, different significant component variables come into play and their structure of combination is different.

An example is seen in the case of people voluntarily changing jobs. For an individual, the meaning of a job change is (almost) invariably favorable as he moves to a more rewarding or more promising job situation, or at least escapes from one that is becoming less favorable. At the level of the firm or the society a change in rate of voluntary turnover (an index obtained by the aggregation of individual events) is totally uninterpretable by itself. Each instance of a job change involves a significant cost, and it is by no means certain that, as for the individual, the benefits exceed the costs. Turnover rates that may be optimum for, say, a rapidly expanding firm might be disastrous for a stable or declining firm. The 'disaster' for a firm might well signal a net benefit for the society in the accomplishment of voluntary and low-cost inter-sector reallocation of manpower. The point is that several different models may be employed in interpreting such an indicator, and the role of the indicator is not the same at all levels of interpretation.

Existing models (theories) concerning the quality of employment make 
it plain that one gets a different product when optimally aggregating information about the quality of employment for a given individual than one does when one optimizes for a society. The relevant and critical variables are to a significant degree different ones, and the meaning of these variables within the different systems of variables is to some degree different and in plausible cases, opposite. (I risk overstating the case. I believe that there will be discovered substantial congruencies in the assessment of the quality of employment at the three levels. Nevertheless, the incongruities can not be ignored for they bear upon our choice of priorities and operational strategies for the next years).

The choices involved may be clarified by the image of aggregating maximally homogeneous data as compared with aggregating maximally complementary data. The former involves relatively simple operations of calculating central tendencies (e.g. averages) and deviations; the latter involves the construction of models of behaving and purposeful systems. ${ }^{11}$ Averaging the hours of work for a society is an aggregation of relatively homogeneous data which produces a valid index that describes an aspect of that society but does not describe any member of it. Combining a diverse set of attributes of a person with attributes of his work environment (complementary aggregation) produces a valid index of the quality of work for that person. Combining a set of varied societal indicators can produce a valid characterization of the quality of employment for that society, but leaves in doubt how well it represents the experience of any member of that society. It is plainly false to assume that the prevailing experiences of persons are embodied in the statistics for a society as a whole, even if these statistics are formed by the aggregation of data about persons. The societal averages decompose the quality of employment into component variables, while the quality of employment for a person is composed of a distinctive set of values on those variables.

The point is so critical that an example is warranted. For a society as a whole, one might reasonable assert that high quality of employment is associated with: (1) low rate of involuntary unemployment; (2) high rate of hourly pay up to the constraints imposed by necessary capital formation and public services; (3) low rate of occupational injury; (4) high rates of productivity per manhour of goods for which there is a market; (5) etc..... For a typical individual worker, the critical variables might include: (1) having a stimulating but not onerous degree of challenge and 
variety in his work activities; (2) having suitable resources of information and equipment to permit doing the job well; (3) receiving pay and other benefits that are equitable in comparison with others; (4) absence of unnecessary hazards, inconveniences, and physical discomforts at work; (5) pleasant work associations with other people; (6) etc.... (Note: the first list is speculative while the latter is based upon empirical sources.) If both lists were extended, and if efforts were made to maximize their congruence, some overlap in the two lists would be found, but never an identity.

It seems plain that the monitoring of the quality of employment will require coordinated conceptions, models and census operations that permit assessment at both the level of individual workers and at the societal level; the levels of work group, firm or industry being, perhaps, optional. Aggregation of diverse variables at the individual level preserves the integrity of the person, permits consideration for individual differences, and constitutes a measure of 'job satisfaction' that is valid for persons. Aggregates of diverse variables at the societal level may preserve the integrity of the society as a system, but may be deceiving as to the life experiences of members of that society.

\section{II.3. Objective vs. Subjective Indicators}

Quite apart from the issues mentioned in the preceding pages, there is the further issue of preference for objective measures, subjective measures or some combination of the two. Social scientists, politicians and managers all share a fondness for 'hard' measures - i.e. those that are thought to be replicable in application and constant in reference regardless of the person of the measurer and without distortion from the individuality of informants. In the context of monitoring the quality of employment, such a view suggests the time serial measurement and societal aggregation of such 'objective' indicators as pay, hours of work, duration of vacations, occurrence of job injuries, rate of promotions, and the like; it suggests the avoidance of such indicators as satisfaction with pay, preference for more or fewer hours of work, need for a vacation, perception of hazard, expectation of promotion, and the like.

The advantages of 'hard' data are too often assumed without question or inquiry; it may be claimed that they are more accurate, can be acquired at less cost, and are less subject to distortion of meaning. Sometimes they 
are. The accuracy and cost arguments we can set aside, as empirically determinable in any given case without conceptual dispute. However, on the issue of the meaning of the data, some distinctions must be made which bear on our arguments concerning the nature of job satisfaction and its role in monitoring the quality of employment.

One of the claims favoring 'hard' data is that they provide a better representation of the realities of life than do the corresponding 'soft' data obtained by the filtering of 'reality' through the person's psyche. The frailty of that proposition can be illustrated easily in the case of pay. To begin with, measures of rate of pay (say, per hour) are not as 'hard' nor as easily acquired as one might at first think. Employers' records, or tax returns, may provide some of the relevant information, but then one must adjust for overtime, take into account the value of indirect pay (differential fringe benefits), consider the impact of avoidable and unavoidable payroll deductions and taxes, and consider the need for further adjustments to take account of the certainty or uncertainty of the continuance of regular pay and the costs of maintaining one's employment. The product of all these acrobatics is an estimate of the effective rate of pay of the person that, with very satisfactory confidence, can be compared with his past pay or someone else's pay or with an estimate of his need for pay. A number of assumptions and estimates go into the process; the data turn out to be less 'hard" than at first imagined (and very costly, we might add, compared to the cost of comparable 'soft' data).

The second weakness of the 'hard' data claim lies in the assumption that the meaning of the data is clear-cut. There is, or at least should be, some correspondence between such an objective indicator and the life experience it is intended to represent. However, the correspondence between objective conditions of life and the directly experienced conditions of life is much less close than is commonly supposed. The correlation between actual rate of pay and job satisfaction directly measured is only about 0.20 (Eta); the correlation between pay and satisfaction with pay itself is only slightly greater. One might suppose that family income, as compared with own income, is the effective objective indicator to represent the experience of income, but that correlation is even smaller. These figures are maximal, being derived from a probability sample of all employed adults in the United States, with the full range of pay included and curvilinearity taken into account. ${ }^{12}$ 
Plainly, rate of pay, however sophisticated and accurate our measurement of it, is not the same as satisfaction with pay. The two variables are measurable with roughly equal reliability, but pay is one thing, satisfaction with pay is something else.

The third weakness of the 'hard' data claim is the presumption that objective data - the objective conditions - strongly determine later events and conditions, while the 'soft' data do so only weakly, as though, for example, pay is expended with readily predicted impact upon later events, while satisfaction with pay has no consequence of importance. Again, the examination of the evidence leaves one with a clear conclusion that for some important kinds of prediction and control of future events, the 'soft' data are more potent and therefore more useful in the formulation of public policies and programs.

Conclusion: In the monitoring of the quality of employment both at the individual and at the collective levels, we shall have to use both 'objective' and also 'subjective' indicators. They are distinctly different kinds of information, are complementary to one another, one can not be substituted for the other, each illuminates the other. Each is particularly pertinent in its own way to the task of understanding the quality of employment; and each feeds a somewhat different system of social action toward the maintenance and improvement of the quality of employment. The "hard indicators appear to be more often useful in the technical design of public programs and associated legislation; the 'soft' indicators appear to be particularly useful in policy and goal formation, in setting priorities, and in evaluating the success of action programs.

\section{THE INDESPENSABILITY OF JOB SATISFACTION MEASURES}

The foregoing arguments have been intended to show that the monitoring of the quality of employment in a society must allow for the following considerations: (1) that several different and competing value perspectives need be taken into account; (2) that assessment must rest upon some models or theories about sets of interdependent variables that jointly express the meaning of quality of employment; (3) that these models or theories must be different in important respects when conceived and measured at the level of the individual citizen as compared with the society itself as a behaving entity; (4) that some significant variables will be com- 
mon to both individual-level and society-level assessment but some will be relevant at only one of the levels; and (5) that subjective measures are needed because they are qualitatively different from and complementary to objective measures, and because they are in many cases superior from a cost/accuracy point of view.

These considerations lead to the dismal conclusion that the monitoring of the quality of employment must give a prominent place, although by no means an exclusive or dominant place, to the direct measurement of job satisfaction and dissatisfaction, and to the continuous surveillance of the conditions of life and of persons that are associated with the experience of satisfaction. I use the term 'dismal' in the belief that most readers will have had some experience with our past conceptions of job satisfaction and some frustrations in trying to apply them to practical affairs. I feel that these frustrations are transient, and that we can build upon the past work to move toward new conceptions of job satisfaction that are more realistic and more useful.

This paper began by pointing out some limitations of our prevailing conceptions of job satisfaction. These limitations can be avoided. They are the target for the remainder of the paper. Job satisfaction is typically conceived to be caused primarily by the job itself, excluding the larger environment of the job; it has been treated as a relatively static state of the person; it has been treated without sufficient respect for time and the implications of past events and future consequences; it has been treated as an outcome of antecedents rather than as a determiner of important consequences. It is suggested that we need to formulate our approach to the measurement of satisfaction as an indicator of the quality of employment with more attention to the following ideas:

(1) We should enlarge our scope of reference. The power of a job, or a work environment, to generate satisfaction depends not only upon the attributes of the job itself, but also and substantially upon the compatibility of the job role with the occupant's larger work role and his associated life roles. The same job may satisfy one person simply because it provides necessities without interfering with his preferred life style; it may equally satisfy another person for an opposite reason, namely, that it embodies more than any other aspect of his life, his dominant values and preferred life style. The fact of satisfaction is shared, but the implications are rather different. 
(2) We should pay attention to the flow of life events, and the satisfying and dissatisfying features of jobs in the context of careers, life spans, and changes in life circumstances.

(3) We should acknowledge that persons keep changing, with maturation and normal life contingencies altering for them the significance and the satisfactoriness of the attributes of their jobs. A man's pay may be highly satisfactory until he acquires a wife and child - events that may well cast a rather new perspective upon his pay packet.

(4) We should observe that satisfaction exists only if daily reaffirmed, that it is not necessarily a constant or even a relatively stable state, that dissatisfaction is in the normal case a transitional state that is changed.

(5) We should acknowledge that direct job satisfaction measures by themselves, no matter how well conceived and operationalized, are potentially deceptive and are best used in conjunction with associated variables that reflect our best models and theories about persons, jobs and their relationships.

\section{THE PSYCHOLOGY OF JOB SATISFACTION}

The measurement of job satisfaction in an individual assumes that: (1) the experience of satisfaction or dissatisfaction produces an attitude regarding a job that arises in part from the objective qualities of jobs and jobassociated conditions, and (2) that such attitudes may be potent factors in the cause or modification of certain kinds of behavior. In short, it is assumed that objective conditions through the mechanism of attitude formation provide a partial 'explanation' of such behavioral outcomes as illness, turnover, absenteeism, and counter-productive behavior. As indicated earlier in this paper, for example, the 1969 Working Conditions Survey in the United States showed that about half of the variance in job satisfaction was 'explained' by the job occupant's report of working conditions and job associated conditions.

It is further assumed that members of the work-force are not wholly uniform in their perceptions of and responses to objective working conditions. Additional satisfaction and behavior variance is explainable by taking into account individual differences as well as the interactions between these differences and the working conditions. For example, it may be possible that individuals of different educational attainments, or of 
different degrees of economic need might respond differently when exposed to the same objective conditions.

This elementary assumption is one basis for searching for individual differences in satisfaction and in satisfaction-related behavioral outcomes, as well as between categories of the work-force defined by common demographic characteristics or measured personality characteristics. Thus, one may ask of survey or census data whether men respond differently from women, blacks differently from whites, or older workers differently from younger ones. Similarly, in the personality domain, one can ask whether persons relatively high in need for affiliation respond differently to the same working conditions than do those relatively low in need for affiliation. Such inquiries with the 1969 Working Conditions survey data (largely excluding 'personality' measures) demonstrated that there were significant differences in response to working conditions for such categories of persons, and that these differences were sufficiently regular and stable to aid in explaining satisfactions and behavioral outcomes in addition to the explanations that were applicable to the whole of the work-force.

More importantly, there is a third type of assumption underlying the measurement of job satisfaction and its consequences, one that has so far been explored only to a very limited extent - the assumption that a given individual is not constant as a responder to working conditions but is subject to highly individualistic differences and to short-cycle changes in his response to working conditions. That is, in addition to the explanation of his reactions arising from his existence as a normal human being in the work-force, and in addition to the further explanation arising from his possession of certain specific explanatory attributes which he shares

TABLE II

Sources of variance in job satisfaction

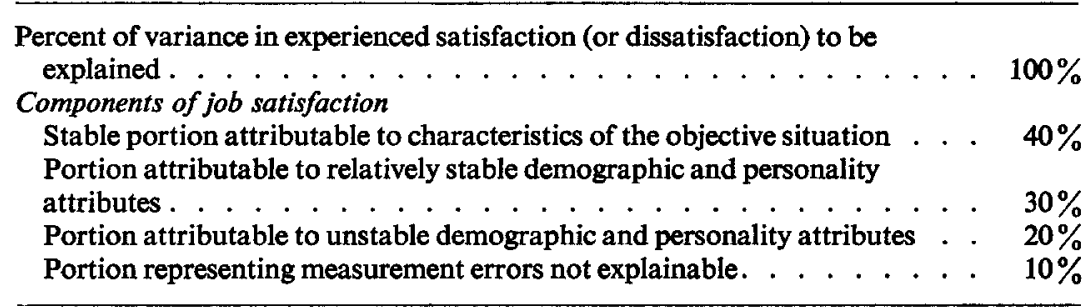


with many but not all other members of the work-force, there is a still further degree of explanation to be sought in terms of transitional and changing attributes which he shares for a time with relatively few other members of the work-force.

These three assumptions can be summarized as in Table II, along with illustrative and highly speculative percentages that represent the accumulative explanatory power of inquiries that encompass all three levels of explanation. ${ }^{13}$

\section{IV.1. Job Satisfaction as an Adaptive Psychological Process}

A worker's experience of job satisfaction, and the generation of behaviors consequent on job satisfaction, is undeniably a psychological phenomenon, therefore in all cases an individual phenomenon. This view is valid even though there may be, and indeed are, constancies arising from the realities of the external world and arising from human uniformities in psychological processes. It follows that a conception of the research issues must rest fundamentally upon biopsychological propositions.

For this purpose the formulation set out by Locke ${ }^{14}$ and others is useful. In essence, this view holds that the human capacity to form attitudes of satisfaction or dissatisfaction regarding a job serves the essential biological function of behavior regulation in the interest of maximizing life sustaining and life enhancing values. Two features of this view are emphasized: (1) job satisfaction and dissatisfaction are of interest in the long run not so much as intrinsic ends to be maximized or minimized by society, but because they affect behavior and thus have important social implications; (2) job satisfaction and dissatisfaction are both to be regarded as potentially and normally of positive value in the maintenance of the integrity and effectiveness of the person. These are emphasized because they are at odds with the usual presumption that job satisfaction is 'good' and job dissatisfaction is 'bad'. Job satisfaction is better regarded as an attitude arising from two concurrent evaluative activities of a continuing nature in which the individual assesses his job and work environment as he perceives them in terms of his assessment of whether they are likely to aid or undermine the realization of his basic values (relatively constant for an adult) and their associated experienced needs (changing in priority with life experiences) and their associated concrete life goals (mainly short-run and changeable as sub-goals are achieved, abandoned, 
or substituted). Job satisfaction is thus a dynamic process although at any given time of measurement it can be treated as a static attitudinal state; the fluctuation of satisfactions and dissatisfactions is emphasized as an expected condition to be taken into account in the explanation of the behavior of individuals in relation to their jobs.

This argument may at first seem unnecessarily global and abstract. It is set out in order to make clear that it is essential in future inquiries that deal with job satisfaction to provide for study at three complementary levels of generalization:

(1) Assessment of the prevailing levels of satisfaction and dissatisfaction for the work-force as a whole, and description of the working conditions that, as a general rule, are associated with satisfaction and dissatisfaction.

(2) Assessment of the prevailing levels of satisfaction and dissatisfaction for large, defined subsets of the work-force - categories defined by common social role and personality characteristics - and descriptions of the manner in which working conditions differentially affect these different categories of people.

(3) Assessment of the changes in job satisfaction and dissatisfaction that accompany typical changes in the person or the work environment of persons, with a view toward discovering regularities (predictability) in such changes.

\section{IV.2. Life Cycle Changes and Job Satisfaction}

Attention should be paid to those individual differences and changes that are of a dynamic, accommodative, and transitional sort, setting aside those individual differences which because of their relative stability over a lifetime are called 'personality'. In considering these differences and changes, the following paragraphs ignore differences of fluctuating kinds that are associated with stable personality differences - for example, individualistic differences in ways of perceiving and cognizing the environment and differences in patterns of abilities that moderate responses to environment. These rather arbitrary exclusions arise because the focus is upon types of individual differences and similarities that are induced by the normal and recurring events of life in any society, and thus can potentially provide generalizations useful for predicting or influencing the satisfaction of other individuals who will go through similar normal life 
experience changes. The differences in question are those that are thought to be most pertinent to the understanding of associations between qualities of the job and the job environment, on the one hand, and responses of satisfaction on the other.

Such 'normal and recurring' events of life and life change experiences need not be detailed exhaustively here. The most obvious ones are those that most or many people encounter as an expected part of their adult years as members of the work force. A worker takes his or her first job and has an initial experience of satisfaction or dissatisfaction. Few people remain in their initial job, and their choice of and response to a new job may well be influenced by the experience of the preceding one. If the job is within an established promotional sequence, or a career line with known advancement stages, response to a job is no doubt altered by knowledge of future potentialities and normally-scheduled career events, and by gradual awareness that these will or will not be realized. An initially challenging job becomes less so as the occupant gains competence by experience; a job may induce a change in satisfaction with gradual realization of relative success or failure in its performance. A person satisfied with the pay and security benefits of his job may alter his reports of job satisfaction with the acquisition or loss of dependents through mariage, birth of children, maturation of children, employment of spouse or approach of retirement. Normal life experience increases with aging the range of available comparative information about alternative jobs and their characteristics. Abrupt changes of economic inflation or changing levels of unemployment may alter the meaning of the characteristics of a worker's own job. Such a list can be extended. What such normal changes have in common is the potential for inducing substantial changes in the experienced satisfaction with a given job, and a potential for changing the relative salience of the values, needs and goals that are invoked by a person in the process of forming and changing attitudes of satisfaction or dissatisfaction.

To study the impact of such normal life changes upon job satisfaction there must be taken into account not only the more-or-less directly observable facts (e.g., tenure in job, change in number of dependents) but also the psychological processes of accommodation. To this end a proposition is advanced below and some of the alternative forms for its expression are indicated. 


\section{IV.3. Accommodative Patterns}

This proposition assumes that there is in the 'normal' worker a persistent force toward the experience of satisfaction and the avoidance of the experience of dissatisfaction, and assumes as well that, experiencing dissatisfaction with the job or some aspect on the job, the worker will seek and find accommodation in some fashion. Thus, dissatisfaction is generally an unstable and transitional state, one that is changed. In support of this assertion, over a span of several decades, estimates of the proportion of 'dissatisfied' workers in the U.S. work-force generally or in specific occupations have remained surprisingly low and only moderately variant; data from the 1969 Working Conditions survey is typical in this respect, ${ }^{15}$ with perhaps 15 percent or 20 percent of the respondents reporting overall dissatisfaction (more or less depending upon the form and content of the job satisfaction measure or question). Further evidence lies in the fact that many workers feel and report satisfaction with jobs that on the face of it do not merit that kind of attitude, being grossly deficient in pay, safety, security, intrinsic interest, and other qualities that are commonly valued. The dissatisfied job occupant will, in the normal case, find ways to change his job or rationalize a change in his evaluation of his job. The accommodative processes and stategies undertaken by an individual to assure job satisfaction may include any one or several of the following:

(1) Changing the job environment. - The worker may change his job and job environment through promotion or transfer, seeking new employment, or exploiting the ever-present latitude for altering the 'same' job within limits allowed by his employer and by his own resources and ingenuity. The many devices invoked by people to make their job situation more interesting, more fulfilling of their needs, more secure, more (or less) responsible, etc., are richly documented. ${ }^{16}$ Few jobs are as fixed in their properties as is implied by labor contracts, job specifications, managerial directives, and the like. An essentially unsatisfactory job may, within limits, be made more satisfactory by the occupant within the terms of employment.

(2) Goal reduction. - The worker may modify his expectations and aspirations, reduce his goals, to bring them into consonance with what he perceives to be the realities of his situation and of feasible alternatives.

(3) Cognitive distortion. - The worker may alter his perceptions of the 
situation and of himself to attain consonance between his values and his experience of the job. The processes of perceptual and cognitive distortion are well established and potent. For example, the person may come to regard his essentially routine and inconsequential job decisions to be 'really critical' to the enterprise; he may revise his assessment of his pay by shifting his reference group. ${ }^{17}$

(4) Resignation. - The worker may adapt to what he believes to be necessary by simply accepting the situation, usually preserving self esteem by allocating blame to others or to 'the system' or to past chance events not now in his control. Such an accommodation may be accompanied by adverse consequences in, say, health or effectiveness.

(5) Aggression. - The worker may respond by aggressive attitudes and acts and these may be directed either toward himself, with consequent mental and physical health pathologies, or toward the situation, with consequences ranging from minimal job performance to disruption and sabotage. The acting out of aggression is itself satisfying and may become a permanent feature of 'the job', a type of fringe benefit as in the case of so-called 'white collar crime'.

(6) Withdrawal. - The worker may gain a partial psychological escape from the dissatisfying situation, usually by altering either his values (e.g., regarding income, skill usage), or by seeking primary value realization in off-work activities, or by leaving the work-force.

These and other strategies for minimizing job dissatisfaction can be differentiated with respect to their implications for work performance, manpower utilization, public health, and community/family welfare and other outcomes listed in Table I. While all of the strategies serve the immediate and compelling function of dissatisfaction reduction, some accomplish this end with a by-product of personal, organizational and societal enhancement, others at a heavy cost.

\section{A SOCIOLOGICAL VIEW OF JOB SATISFACTION}

The preceding section focussed upon the role of job satisfaction and dissatisfaction in the life of the individual, to show that the process of forming and changing such attitudes regarding employment goes beyond humanitarian or narrowly scientific interests. For the individual, job satisfaction is a desired state that is continuously experienced and maintained, if 
possible, within a continuously changing environment and within a continuous flow of changes in his own person. When satisfaction is not present, the individual seeks and normally achieves some sort of accommodation. The ease of accommodation, and the choice of adaptive, rather than pathological accommodations, are accordingly matters of individual origin and primarily individual concern, but in the aggregate they are of vital concern for the social system. The social significance of job dissatisfaction is that it causes people to do things, or to have things done to them, that may be socially constructive or destructive.

The reasons for suggesting a concern about job satisfaction at the societal level, expressed in the development and use of social indicators, are quite obvious: (1) pathological accommodations to job dissatisfaction, if sufficiently persistent and widespread, can threaten the stability of the society and its accomplishment of its goals; ${ }^{18}$ (2) the societal costs arising from the side effects of delayed or pathological accommodation can be a serious drain on the resources of the society; 19 (3) in a changing world, a high value must be placed upon the society's capacity to accommodate quickly and easily to events that alter the kinds of work that need to be done, and therefore the structure of jobs, organizations and occupations - this accommodation must be accomplished largely by individual workers through their voluntary actions, and the dynamics of job satisfaction and dissatisfaction come into play; ${ }^{20}$ (4) every society needs to have an early alert capacity for detecting system dislocations and considering corrective programs, and social indicators regarding job satisfaction provide one (among many) resources for this purpose. ${ }^{21}$ Note that these four reasons for being concerned about job satisfaction all bear on the task of maintaining a viable society.

The relatively primitive state of the technology for societal assessment of job satisfaction and its causes and consequences need not be a deterrent. Parts of this paper are given to pointing out the deficiencies of our present ideas and methods and suggesting directions for improvement. However, the existing and well-tested methods are adequate for initial use and in any case they can be significantly improved only through experience in their use on a societal scale.

The uses of social indicators relating to job satisfaction are likely to take place in three broadly differentiated ways: (1) as a gross assessment of the state of the society and trends of change; (2) as an essential aid in 
developing a further understanding of the nature of the work system of the society and the relation of people to their work; (3) as an aid in the formulation of action programs and supporting legislation to the end of maintaining and improving the quality of employment.

\section{V.1. Gross States and Changes}

The intent of social indicators is, first, to provide a dependable description of the society, and of major segments of the society, with respect to some significant dimensions. It is relatively simple, given the ease of sample surveys, to obtain measures of the degree of job satisfaction that is prevalent among employed people, and of the principle attributes of their jobs and work environments that contribute to their satisfaction and dissatisfaction. This has been done for the United States. ${ }^{22}$ Inquiry of a similar kind has been carried out or is in progress in other countries.

However, an index measurement of, say, the proportion of employed people who are satisfied at a given time has very little meaning by itself. For the United States, in 1969-70, 85 per cent of the employed adults classified themselves as being, on the whole, at least 'somewhat' satisfied. At this time no one knows with confidence whether the percentage of satisfied employees is rising or falling, whether the percentage is higher or lower than in other societies, or whether the $15 \%$ rate of dissatisfaction is cause for alarm or for reassurance. Trends over time can only become known through continuous or periodic measurement using replicable methods. (A replication of the 1969-70 survey is now in analysis.) The comparison among societies will be feasible only after there is some agreement among nations to the end of having some comparable social indicators (initiatives are being taken). The degree of alarm that is justified is not self-evident, not determinable from trends and cross-national comparisons; it depends upon an analysis of the specific causes of dissatisfaction that are operating, the existing adequacy of self-corrective mechanisms, and on the possible concentration of the dissatisfaction within critical segments of the society.

The arguments put forward in the prior section of this paper suggest that the occurrence of job dissatisfaction is quite a normal and inevitable thing, and within limits a desirable thing for a society in that dissatisfaction is temporary for the individual and stimulates necessary societal adaptations and changes. If this view is valid, then we can anticipate that 
gross rates of job dissatisfaction in any large and diverse society may remain quite stable, or at least display changes that are slow in developing and limited in range. This will be a 'dynamic' stability, concealing a good deal of change as to who is dissatisfied and for what kinds of reasons. On these grounds, one can expect gross national level time series indices of job satisfaction to be rather uninteresting and uninterpretable, barring some major and disruptive changes in the society.

For the for seeable future, the utility of job satisfaction as a social indicator will lie in its use in understanding critical changes within the social system, and in its use as an aid in the planning of action steps.

\section{V.2. Understanding the Work System}

Rensis Likert has made a distinction between the use of social indicators for describing the stute of a social system, and their use in discovering and continuously monitoring the nature of the system ${ }^{23}$. By the nature of the system, he means "... the basic conceptual model or understanding which serves as a guide to tell what dimensions of the nation, or society or economy should be interpreted in making decisions." The societal response to crisis, or to perceived opportunity for social improvement hinges on the latter use of indicators such as those for job satisfaction. The specific uses of indices for job satisfaction will be large in number and diverse in kind. They will include, for example:

(1) Determining the set of personal values (preferences) that are used by workers in evaluating their present employment, their motivation to change and their choice of actions. These value priorities may be different for unlike segments of the work force and will no doubt change over time. This knowledge is essential for understanding what constitutes a 'good' job in the eyes of different categories of workers, and what kinds of changes might be beneficial, or might produce negative side-effects.

(2) Tracing the delayed and diffused consequences of substandard conditions of employment - consequences that are important to the society (e.g. premature death, welfare costs, etc.) but not evident to the individual worker until it is too late for him to take preventive action on his own.

(3) Tracing and understanding the impact of sub-standard conditions of employment upon other aspects of the lives of workers, upon their families, upon their communities. 
These are examples only, and other comparable inquiries will be needed to understand the meaning and action implications of social indicators of the quality of employment. Such inquiries are analagous to those long in regular use with reference to other social indicators, such as economic indicators, and are not novel in their conception or method. There follows a brief review of, for illustration, one such enquiry that has been carried out with survey information from a probability sample of U.S. employed persons. ${ }^{24}$

\section{V.3. What is a 'Good' Job?}

One of the questions asked of our survey data was. "What attributes of the job and the work environment contribute to job satisfaction, and what proportion of job satisfaction is accounted for by these attributes?" To treat this question, we began with all available measures describing each person's job and its immediate work environment, removed those of low reliability, high redundancy or severely limited applicability, leaving a varied roster of 33 descriptors. A table was then constructed representing, for each of these descriptors, estimates of its contribution to net job satisfaction, using as estimates both uncorrected correlations (Eta) and also Beta-weights (which show the unique contribution of each job attribute after removal of redundancy with all other attributes).

A few examples will illustrate the kind of information resulting from such a procedure. The job attribute of 'Using the respondent's available skills, with Eta-rank of 5 and Beta-rank of 1 (out of 33) is a strong contributor to job satisfaction by both indicators. The attribute 'Having enough machinery and equipment to do the job well' has a middle level of contribution (ranks of 21 Eta-rank, and 16 Beta-rank). A weak job attribute, although one that workers frequently mention as a problem encountered in connection with their work, is the amount of time required for travel to workplace (ranks of 32 and 30, respectively). An instance of rank discrepancy is displayed by the attribute 'Rate of income from the job', which has ranks of 22 and 9 , indicating that it is relatively weak as to correlation with job satisfaction, yet the basis of this association is relatively unique (non-redundant), so that its contribution to net job satisfaction is shown to be significant.

The several descriptors of job attributes were found, as expected, to be organised in the minds of workers, and therefore not simply a miscella- 
neous list of job attributes. By procedures of factorial analysis, cluster analysis, and related methods, it was ascertained and validated that the significant attributes of jobs and work environments, in relation to net job satisfaction, reflect four (possibly five) underlying dimensions of value. To these analytic dimensions we have given names as follows: Challenge (a factor including such job attributes as its variety, its growth and learning properties, its autonomy, etc.), Resources (sufficient physical equipment, information, and help to do the job well), Comfort and Convenience (convenient work schedule, few dangerous or unhealthy conditions, pleasant and confortable physical surroundings, easy transport to work, etc.), Financial Rewards (pay, fringe benefits, low risk of job loss, etc.) and Relations with Others (a very weak factor concerning relations with supervisor, with co-workers).

The 33 descriptors jointly account for about half of the variance in job satisfaction. The five factors are not equally powerful in 'explaining' job satisfaction, as shown, for example, in their relative beta-weights in an optimizing predictive formula: Challenge 0.17; Resources 0.08; Comfort and Convenience 0.03; Financial Rewards 0.01; and Relations with Others being negligible in this context.

These results were quite stable when subjected to cross-validation and to testing for their applicability to various subpopulations that make up the work force.

What kinds of conclusions may be suggested from data of this kind in the context of our discussion? I suggest two observations as examples. First, when workers assess the quality of their employment they give strong priority to those attributes of their jobs and work environments that pertain to challenge, to accomplishment, and to having the resources that permit effective work, and they give relatively small consideration to the amount of financial rewards. (But note that their beliefs about the equity of rewards, as compared with actual amounts, may be very important, and that actual rewards are no doubt important to those in the lowest income categories.) Second, I would observe that this conclusion appears to hold for people in a wide variety of occupations from highly-paid professional work to relatively low-paid service work; we need to accept that values additional to monetary and security values must be taken into account when attempting to monitor and improve the quality of employment in a society. 


\section{V.4. Program Planning and Assessment}

The function of social indicators must go beyond the mere description of a society to the point of stimulating and guiding action toward agreed social changes. Virtually all countries now have legislation and various programs - both public and private - for achieving at least minimally acceptable standards of employment. We can expect more efforts of these kinds. Most programs, until recently, have been concerned with minimum standards rather than optimum ones, and with indirect actions to soften the effects of sub-standard employment. It is useful now to comment upon the feasibility and necessity of direct action to improve the quality of employment.

There is still prevalent the traditional view that the quality of employment in a society, aside from minimum welfare protections, is fully determined by the state of production technology coupled with the implacable forces of economic process. While it is undoubtedly true that constraints on the quality of employment arise from technology and the general state of an economy, it is also known, in reverse, that the quality of employment may impact upon the technology and economy of a firm or of an industry, and probably (although this has not yet been investigated seriously) upon the whole of the society. ${ }^{25}$ It can be argued that, as a domain of direct action and of public policy, the quality of employment is readily accessible for action, and in some circumstances can and should have priority over economicand technological measures for the enhancement of the quality of life.

The relevance of social indicators regarding the quality of employment - and specifically of aggregated indicators of individual job satisfaction and dissatisfaction - seems quite clear. Here are some examples of feasible and necessary uses:

(1) Locating 'hot spots' in the society. The quality of employment in a society is never uniform, and a prevailing high level of quality can conceal segments of society that are grossly disadvantaged, or unnecessarily bypassed in ameliorative efforts. Quality of employment survey data is singularly useful for assessing allegations of disadvantage or getting early warning about societal dislocations. Current studies in the United States and elsewhere are serving to clarify the special problems encountered by such categories as Negroes, young women, blue-collar workers, the selfemployed, and the like. ${ }^{26}$ 
(2) Legislative priorities. Legislation of a controlling (minimum standards) or enabling (program funding) kind is often designed and enacted in a vacuum as to reliable information about the extent, nature and location of the target problem. It is readily feasible with present social indicator technology to monitor the frequency of occurrence and the experienced severity and the location in the occupational structure of job problems.

(3) Program assessment. All public programs, and private programs as well, of any substantial scope need to be associated with some provisions for finding out whether the intended objectives are achieved and what side effects or unintended consequences may develop. Programs intended to improve working life can readily be so assessed, and programs of other kinds that may have overflow impact on the quality of working life may be so assessed.

(4) Realistic bargaining. It is a common complaint on the part of both management and labor people that bargaining tends to be limited to matters of short-run implication and to familiar issues involving 'hard' information - wages, hours, job rights, and the like. Realistic bargaining regarding non-monetary conditions of work, and longer-range conditions (career opportunity), and the environments of jobs (work improvement, areas of worker self-determination, etc) only rarely enter into negotiations despite awareness of their importance to workers. Familiarity with the nature of social indicators, and the technology for their use, is essential if the future needs of a society are to be met in this regard.

\section{University of Michigan}

\section{NOTES}

* This paper was prepared for the Symposium on Social Indicators of the Quality of Working Life, Canada Department of Labour, 1973, and is printed with permission. The preparation was facilitated by the Netherlands Institute for Advanced Study in the Humanities and Social Sciences, Wassenaar.

1 Examples include the international network of collaborating social scientists being formed under the auspices of the University of California at Los Angeles, and the series of coordinating conferences conducted by OECD.

2 The following section and some later ones draw freely from prior papers, including: R. P. Quinn, S. E. Seashore, E. Yuchtman and B. F. Strumpel, 'The Personal, Corporate and Societal Implications of Quality of Employment: Some Issues of Strategy, Theory and Method', a technical report submitted to the Workplace Standards Admini- 
stration of the U.S. Department of Labor, 1972; S. Seashore, 'Defining and Measuring the Quality of Working Life', to appear in Quality of Working Life: Problems, Prospects and State of the Art, Free Press, New York 1975; S. Seashore, 'Societal Implications of the Quality of Employment', in B. Biervert et al. (eds.), Konsum und Qualität des Lebens, Westdeutscher Verlag, 1974

${ }^{3}$ R. L. Kahn, 'The Meaning of Work: Interpretations and Proposals for Measurement', a chapter in The Human Meaning of Social Change (A. Campbell and P. E. Converse, Eds.), Russell Sage Foundation, New York, 1972.

4 J. T. Barnowe, T. W. Mangione and R. P. Quinn, in The 1969-1970 Survey of Working Conditions: Chronicles of an Unfinished Enterprise. Survey Research Center of the Institute for Social Research, 00 1973, Ch. 9.

5 Survey Research Center, Survey of Working Conditions: Final Report on Univariate and Bivariate Tables, Document No. 2916-0001, U.S. Government Printing Office, August 1971, p. 484.

6 S. E. Seashore, B. Indik and B. S. Georgopoulos, 'Relationships among Criteria of Job Performance', Journal of Applied Psychology 44 (1960), 195-202.

7 D. G. Bowers and S. E. Seashore, 'Predicting Organizational Effectiveness with a Four-Factor Theory of Leadership., Administrative Science Quarterly 11, (1966); Number 2; E. Yuchtman and S. E. Seashore, 'A System Resource Approach to Organizational Effectiveness', American Sociological Review 32 (1967) Number 6.

${ }^{8} \mathrm{~S}$. Cobb and R. M. Rose, 'Hypertension, Peptic Ulcer and Diabetes in Air Traffic Controllers', Journal of the American Medical Association 224 (1973) Number 4.

9 Yuchtman and Seashore, op. cit.

10 Some of the issues to be discussed are treated with greater detail and clarity by A. D. Biederman, 'Social Indicators and Goals', in Social Indicators (R. A. Bauer, Ed.), the M.I.T. Press, Cambridge, 1966.

11 See Biederman, op. cit., for examples of the complexity of 'simple' indices, many of which must go through complex adjustments to be made at all useful. See R. Ackoff and F. Emery, Purposeful Systems, Tavistock, London, 1972, for an illustration of the theoretical model-building process; see Barnowe, Mangione and Quinn, op. cit., for an example of empirical model construction.

12 Survey Research Center, op. cit.

13 Ignored here are two further sources of variance, one arising from the short-term variations that normally occur in the objective characteristics of 'the same' job, and the other arising from interactions among the factors that are here treated as being simply additive. For methodological reasons, the second percentage is shown as $40 \%$ instead of the emprically obtained $53 \%$; the latter may be an overestimation.

14 E. A. Locke, 'What is Job Satisfaction?', Journal of Organizational Behavior and Human Performance 4 (1969) Number 6.

15 Barnowe, Mangione and Quinn, op. cit.

16 W. F. Whyte (Ed.), Money and Motivation, Harper, New York, 1955.

17 M. Patchen, The Choice of Wage Comparisons, Prentice-Hall, Englewood Cliffs; 1961.

18 H. L. Sheppard and N. Q. Herrick, Where Have all the Robots Gone? Free Press, New York, 1972.

19 Work in America, a report of a special task force to the Secretary of Health, Education and Welfare, December, 1972. See Chapter III, 'Work and Health'.

20 J. B. Lansing and E. Mueller, The Geographic Mobility of Labor, Institute for Social Research, Ann Arbor, 1967.

${ }^{21}$ Sheppard and Herrick, op. cit. 
22 Survey Research Center, op. cit.

23 R. Likert, 'The Dual Function of Statistics', Journal of the American Statistical Association 55 (1960). Number 1.

${ }^{24}$ Barnowe, Mangione and Quinn, op. cit.

25 See selected papers and case reports from the proceedings of the International Conference on the Quality of Working Life. These will appear in two volumes from Free Press, Quality of Working Life (op cit.) edited by L. E. Davis and A. B. Cherns. ${ }^{26}$ See: 'Sex Discrimination Against the American Working Woman'; 'The Now Generation of Workers'; 'The Relationship between Quality of Employment and Job Satisfaction for Black and White Workers'; 'The Disadvantages of Organizational Membership: Myth or Reality?'; ' Demographic and Job Factors Associated with the "Blue Collar Blues"; all appearing in Quinn, et al., The 1969-1970 Survey of Working Conditions; Chronicles of an Unfinished Enterprise, op. cit. 